Int. J. Dev. Biol. 50: 123-134 (2006)

doi: $10.1387 / \mathrm{ijdb} .052043 \mathrm{sb}$

\title{
Principles of branch formation and branch patterning in Hydrozoa
}

\author{
STEFAN BERKING* \\ Zoological Institute, University of Cologne, Köln, Germany
}

\begin{abstract}
The freshwater polyp Hydra produces buds which separate from the parent. Other Hydrozoa produce branches which remain connected to the parent, thus forming a colony. Some Hydrozoa grow by means of an organ that is like a shoot apical meristem. Others display a sympodial type of growth. In this article, I propose that these different types of branches are organized by a common pattern-forming system. This system has self-organizing properties. It causes branch tip formation and is kept active in the tip when the tip finally differentiates into a hypostome of a polyp. The system does not cause structure formation directly but rather, determines a tissue property called positional value, in such a way that a gradient of values forms in the tissue of the bud or branch. The local value determines the local morphodynamic processes, including differentiation of the hypostome (highest positional value), tentacles and basal disc and of the exoskeleton pattern along the shoot. A high positional value favors the onset of a new selforganizing process and by lateral inhibition, such a process prevents the initiation of a further process in its surroundings. Small quantitative differences in the range of the signals involved determine whether a bud or a branch forms and whether monopodial and sympodial growth follows.
\end{abstract}

KEY WORDS: Hydra, pattern formation, budding, sympodial growth, monopodial growth

\section{Introduction}

The best known member of Hydrozoa is the freshwater polyp Hydra, which can reproduce asexually by budding. The bud develops somewhere in the middle between the apical and the basal end of a polyp, out of a group of somatic cells (Fig. 1A, B). A bud develops into a small polyp and separates from the parent. Marine Hydrozoa generally produce colonies, of which some resemble seed plants. As in plants, two parts can be distinguished (Fig. 2B). The basal part, called the hydrorhiza (or stolon), forms a network of hollow tubes that branch and that may reunite. This part fixes the organism to a substrate. The apical part consists of the hydrocaulus (or shoot), which may branch as well. A tip of such a branch usually ends in a polyp (or hydranth). The polyps of such colonies have a structure similar to Hydra. In some species the tip keeps its state of a growing tip, like the shoot apical meristem in seed plants. Some authors consistently call this organ a cormus (for example, see Kühn, 1909, 1914; von Schenck, 1965). The most elaborated branching pattern structures a subgroup of Hydrozoa called Thecata. In this group two types of shoot growth appear, sympodial and monopodial growth.

The questions are, What mechanism of pattern formation is common to all Hydrozoa? and How do we modify the common principle to account for the observed diversity of branch patterning? In the following discussion I compare observations and ideas concerning the control of pattern formation and concerning the morphodynamics of budding and branch formation in the various Hydrozoa. Models of pattern formation in Hydrozoa were generally designed to explain results obtained from regeneration and transplantation experiments. The models assume the existence of morphogens that are generated by the head and the foot, respectively. These morphogens are proposed to control the formation of these structures and the differentiation of the tissue along the body axis. The best evolved model of this type is that developed by Meinhardt (1993). In colonial hydroids, polyps develop far away from a basal disc and Kosevich (1991) has shown that the tissue of the future hypostome, exclusively, controls the patterning of the branch, including the formation of the polyp. In colonial hydroids a foot system either does not exist or does not influence branch/polyp formation and the patterning of the polyp. Clearly, for developing a concept of pattern control that is common to all Hydrozoa, such differences are particularly important. Unquestionably a common principle exists; but which elements of pattern control and morphodynamics are common to

\footnotetext{
*Address correspondence to: Dr. Stefan Berking. Zoological Institute, University of Cologne, Weyertal 119, 50923 Köln, Germany.Fax: +49-221-470-5171. e-mail: s.berking@uni-koeln.de
} 
all Hydrozoa and which have evolved by modifications of the existing ones and by "inventions" later on in the various species?

\section{Results and Discussion}

\section{Hydrozoa that produce Branches which separate from the parent animal: vegetative reproduction}

The best known member of this group of Hydrozoa that produce branches that separate from the parent animal is the freshwater polyp Hydra, which has a tube-shaped body (Fig. 1). One end consists of the head, with the mouth/anus opening surrounded by tentacles. The other end, called the foot, includes the basal disc that closes the tube. The middle part is the gastric region. The body wall has two layers, the ectoderm and the endoderm, separated by an extracellular matrix, the mesoglea. Hydrais famous for its ability to regenerate. Small body sections of Hydra give rise to complete animals: The head regenerates from the apical end and the foot from the basal end. This indicates a polar organization of the tissue. Tissue pieces obtained from different body levels display different capacities to transform into a head or a foot, respectively, when transplanted to a host animal. The tissue taken from a more apical position combines a higher capacity to form a head with a lower capacity to form a foot. The polarity of the tissue and the graded distribution of the noted capacity is determined by a scalar tissue property (Gierer et al., 1972) that has been termed positional value (Wolpert, 1969; Wolpert et al., 1974) or source density (Gierer and Meinhardt, 1972). By definition, the posi- tional value (or source density) has its highest value at the apical end of a Hydra and its lowest value in the basal disc.

In Hydra, budding visibly starts with the formation of a small protrusion of both tissue layers of the parent's body wall (Fig. 1). The bud grows by recruiting tissue of the surroundings and by cell multiplication (Otto and Campbell, 1977). The tip of the bud develops into the apical tip of the new polyp's head. The most basal part of the bud develops a basal disc and then the bud separates from the parent. When the tip visibly forms, all body parts of the future bud, including the basal disc, are already determined in form of concentric rings in the parent's tissue (Sanyal, 1966; Tardent, 1972). Thus the formation of head, gastric region and foot is organized from one point, namely the future hypostome of the bud. Obviously, this finding poses problems to models with symmetric opposing gradients of head- and foot-specific morphogens. In the following discussion, I propose an alternative that overcomes these problems.

\section{A model for pattern control in Hydrozoa}

When an adult animal displays a gradient of positional values from one end to the other along the body axis, a bud must also develop this gradient. The proposition is that at the future bud's tip, signals are generated that cause a rise of the positional value up to the maximal value and, some distance away, cause a decrease down to the lowest possible value. In between, a gradient of positional values develops. In a second step, secondary systems control the local development, including the formation of hypostome and basal disc, according to the
Fig. 1. Bud formation in Hydra. (A) Sketch of a Hydra bearing a young bud. The different textures indicate the various body regions of the adult animal and the respective future body regions of the bud (from Sanyal, 1966). On the left the respective positional values are shown. (B) Shown is a sketch of the process of budding lafter Tardent, 1978) and (C-E) a simulation of this process in a piece of tissue representing the budding region with the model proposed (Berking, 2003). Three morphogens control the onset of budding and bud development: an activator $A$ (shown in green), an inhibitor $B$ (brown) and an inhibitor C (blue). These morphogens interact with each other and control the increase and the decrease of the positional value (red). The equations used for the simulation may be interpreted as follows: the positional value of a cell is determined by its content in compound A (activator). The activator is produced within the cells, increasing the positional value. The activator can be released from the cells, decreasing the positional value. The released activator stimulates both its release out of cells and its production within cells. Thus two loops of autocatalysis operate. Further, the released activator stimulates the release of two inhibitors (heterocatalysis). In the released form, one of them (B) antagonizes (counteracts) the release of the activator out of the cells, the other (C) antagonizes (counteracts) the production of the activator within the cells. Alternative interpretations of the equations are possible. The self-enhanced release of the activator depends on the existence of some activator outside the cells. It is assumed that there is a basal unregulated release, the rate of which correlates with the amount present within the respective cell, that is, with its positional value. (C) In the budding region the morphogens and the positional value initially display an almost flat distribution. (D) Because of the interactions of the morphogens that have been noted, the positional value changes such that (E) a complete bud develops, including head and basal disc.
B
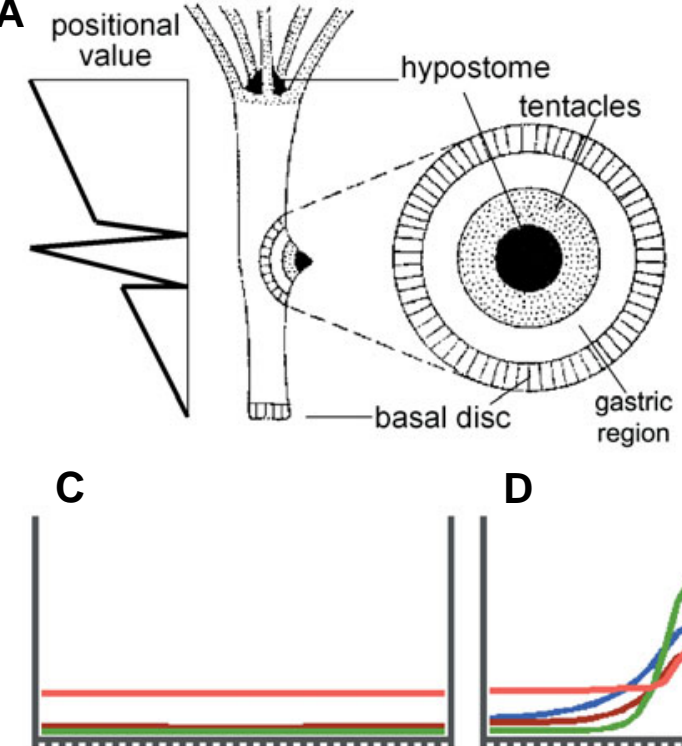

D

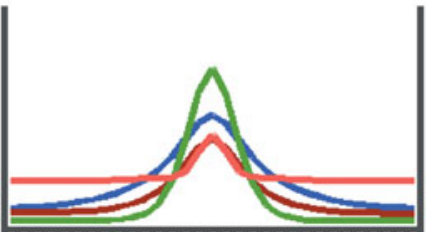

E

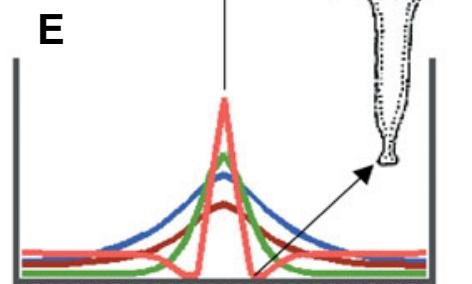


A

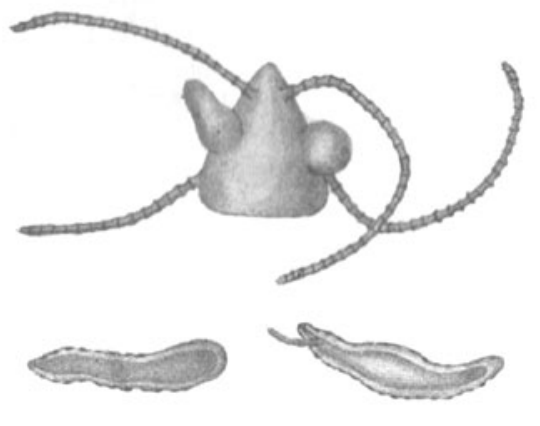

B

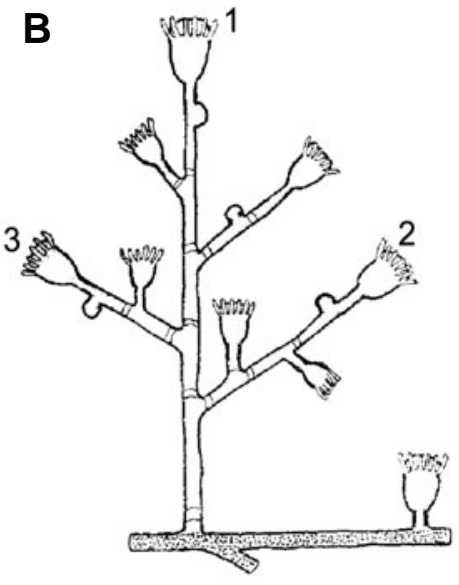

Fig. 2. Frustule formation in Haleremita (Hydrozoa) and monopodial growth in colonial athecates (Hydrozoa). (A) A polyp bearing two frustules and two frustules that have been separated from the parent. The tip of the frustule becomes the future polyp's head. Several days after separation, the first tentacles develop (Kühn, 1914). (B) Sketch of a monopodially growing colony with a terminal polyp (Athecata). Right part: A polyp has formed on top of a stolon (dotted). Left part: The distance between the first formed polyp (1) and its origin at the stolon has increased by intercalary elongation of the tissue tube (coeno-sarc) and by terminal elongation of a possibly existing perisarc covering, that is, just proximal to the polyp (hydranth). A hydrotheca does not exist. At the time the hydrocaulus (both coenosarc and a possible perisarc covering) had reached a certain length, laterally a bud has formed that developed at its end into a polyp (2). After further elongation of the main hydrocaulus, a third polyp (3) has formed and so on (after Kühn, 1914). local positional value attained.

To get an increase of the positional value at one point, namely the future bud's tip and to get a decrease some distance away, two signals with a different range are sufficient when both are generated from that point: One signal increases the positional value; this signal has a short range. The other decreases the positional value; this signal has a long range. Gierer and Meinhardt (1972) have solved the problem of how a group of cells (in this case, cells of the future bud's tip) is prompted to do something different from cells in the surroundings (in this case, cells of the gastric tissue). At the simplest an activator stimulates its own release from cells (autocatalysis or self-enhancement) and the release of an inhibitor, which in turn antagonizes self-enhancement.

A combination of the two propositions can explain budding, including foot formation at its base and various other features of pattern formation (Berking, 2003). The combination made is such that as few compounds as possible and as few interactions as possible, are included: (1) One and the same activator, which by means of autocatalysis (self-enhancement) and lateral inhibition determines a patch of cells to generate both the activator (A) and its antagonist (inhibitor $B$ ). (2) The generated activator causes an increase of the positional value and (3) where the concentration of $A$ is high, a second inhibitor (inhibitor $\mathrm{C}$ ) is generated that decreases the positional value. The range of both inhibitors is larger than the range of the activator. With respect to branch formation in the different species discussed in the following, it is particularly important which one of both inhibitors $\mathrm{B}$ or $\mathrm{C}$ has the longer range. I emphasize that this model does not postulate the aprioriexistence of a gradient and a body length axis. Rather, it proposes the existence of certain interactions or system properties. These interactions generate gradients of positional values and thus a body axis, branches and so on (see Fig. 1).

\section{Patterning of the bud}

Simulation experiments with the proposed model describe bud formation appropriately (Fig. 1). The tip of the bud develops into the bud's hypostome. At the base a foot forms, without footspecific morphogens displaying a long range. The patterning of the bud is exclusively organized from the center, which develops into the new animal's apical end. Arguments for a continu- ous increase of the positional value preceding hypostome formation were derived from the transplantation of regenerating tissue (Berking, 1979). Further, during head regeneration staining of tissue with a tentacle-specific antibody indicates that the tissue that ultimately forms the hypostome (maximal positional value) initially has properties characteristic of tentacles (Bode et al., 1988).

\section{Positioning of the bud}

The pattern-forming system that controls bud development is generally assumed to remain unchanged during the bud's further development. Among other consequences, the system determines the position at which the former bud produces a bud by itself. Two opposing forces control this position: On the one hand, budding tends to start as close as possible to the existing head; and on the other hand, budding is prevented in the vicinity of the parent's head (Burnett, 1961; Webster and Hamilton, 1972; Shostak, 1974; and, with respect to marine animals and polyp formation on stolons, Braverman, 1971; Plickert et al., 1987). The models describe this feature correctly (Meinhardt, 1993; Berking, 2003).

A high positional value favors the self-enhanced release of the activator, causing a bud to form as close as possible to the head. In contrast, the inhibitor involved in lateral inhibition allows the onset of budding only at a certain distance from the head. In other words, one self-organizing process prevents the onset of a further one close to it.

In Hydra the bud develops from tissue of the gastric region of a polyp. In most marine Hydrozoa, a bud or branch does not develop from a polyp but rather from the stolon or from the shoot (hydrocaulus). The reason for that difference appears to be that the polyp Hydrais comparatively large. In Hydrathe bud field of $1 \mathrm{~mm}$ in diameter gives rise to a young bud about $1 \mathrm{~mm}$ long. Most polyps of Hydrozoa that form marine colonies are even smaller. The bud of Hydra grows up to $1 \mathrm{~cm}$ in length by multiplication of epithelial cells, which occurs almost randomly in the body column but excludes the very ends (David and Campbell, 1972). This causes the initial steep gradient of positional values to become flat. However, the range of morphogens is not stretched accordingly. Morphogens generated at the apical end barely reach the basal disc. This allows budding from the gastric region of the polyp. In animals with 
small polyps, the bud field can be expected to match almost the size of the polyp and the range of the morphogens, in particular of the inhibitor that antagonizes the onset of budding, exceeds the size of the polyp (Braverman, 1971; Plickert et al., 1987).

\section{Frustule formation}

Polyps of certain Hydrozoa produce so-called frustules (Fig. 2A). A frustule is a bud without head structures. After separating from the parent, the frustule moves for days or weeks over the substrate; then a mouth and tentacles develop. Finally the frustule has transformed into a normal polyp. It appears that initially at the tip of the frustule the maximal positional value attained is too low to cause head structures to form. Simulation experiments showed that when both the positional value and the level of inhibitor $B$ are reduced, a frustule forms (Berking, 2003). To explain why such a process does not occur in Hydra, we must assume that in the tissue between the budding region and the basal disc, where the positional value is low enough for frustule formation, the concentration of inhibitor $B$ is too high.

\section{Certain manipulations cause a bud of Hydra to develop into a branch}

Two experiments are discussed next. (1) When animals bearing a young bud are sectioned just apical to the bud, the bud transforms into a branch without signs of foot formation (Fig. 3A). At the same time head regeneration is prevented (Weimer, 1928; Rulon and Child, 1937; Sanyal, 1966; Tardent, 1972). (2) Transplanting small pieces of hypostomal tissue to a certain position along the body length axis causes the outgrowth of an axis (branch or bud), as does transplanting a head with the hypostomal tip in front (Fig. 3B): When a head is transplanted to between the head and the budding region, a branch develops. When a head is transplanted to between the budding region and the foot, a bud develops, which detaches from the parent (Berking, 1979). Computer simulation shows (Fig. 3C) that a slight increase of the concentration of inhibitor $B$ in the bud and in the tissue surrounding the bud stimulates branch formation without a foot and without separation from the parent (Berking, 2003). With respect to the experiments mentioned, head-regenerating tissue in close vicinity supplies the bud with additional inhibitor B and tissue transplanted close to the head is expected to get a higher level of inhibitor B than does tissue far away from the head. In contrast, a developing bud also generates the (hypothetical) inhibitors. Thus a developing bud can antagonize head regeneration and bud formation in its close vicinity.

The model also describes head and foot regeneration. Head regeneration is simple to understand; it is similar to the onset of budding or branch formation. Foot regeneration is more difficult to understand. Simulation experiments showed that the very same morphogens control both head and foot regeneration. The tissue property (positional value) adjacent to the former wound determines whether the positional value increases or decreases. In particular, the net export of the inhibitor that causes a decrease of the positional value was found to be decisive (Berking, 2003). This feature of the model is shown in a simulation of pattern formation in Dynamena (see Fig. 5 and Fig. 6). The system is kept active in the tip when it differentiates into a hypostome and is finally switched off when the tip differentiates into a basal disc.

In summary: A pattern-forming system including at least three morphogens is proposed to control the quantity of a tissue parameter, namely the positional value and thus generates a body axis starting from homogenous conditions. The local value determines local development. The model can describe budding as well as head and foot regeneration. In tissue of high positional value, the onset of a new self-organizing process is favored. Whether a bud or branch forms depends on lateral influences and on the property of the tissue that may form the basal disc. By lateral inhibition, one self-organizing process prevents the onset of a further, nearby self-organizing process.

\section{Hydrozoa producing branches which persist at the parent animal: colony formation}

Most Hydrozoa form colonies. Colonies generally consist of two parts: a net of tubes (termed stolons or hydrorhizas) fixed to a substrate and polyps (hydranths) on top of these stolons (Fig. 2, Fig. 4). The polyps look similar to a Hydra. The simplest colonies produce polyps directly on the stolon. Complex colonies form shoots made of repetitive elements on which polyps form in a regular pattern.

Shoots form in two ways. Either the stolon tip transforms into a shoot tip, resulting in a polyp at its end, or a shoot forms on top of a stolon. Such a tip displays shoot quality from the outset. A satisfactory explanation for the transformation of a stolon tip into a shoot tip and the reverse-observed, for example, in Plumulariidae, which are thecate Hydrozoa with a monopodial type of growth (von Schenck, 1965)-appears to be a challenge for models of pattern control. The problem is that if morphogens specific to head and stolon tip are assumed to control the two different tips, we must explain how the self-enhanced generation of stolon-specific morphogens ceases while that of a polyp's head starts and takes over (and the reverse). In the model I propose in this article, one system with three morphogens controls the

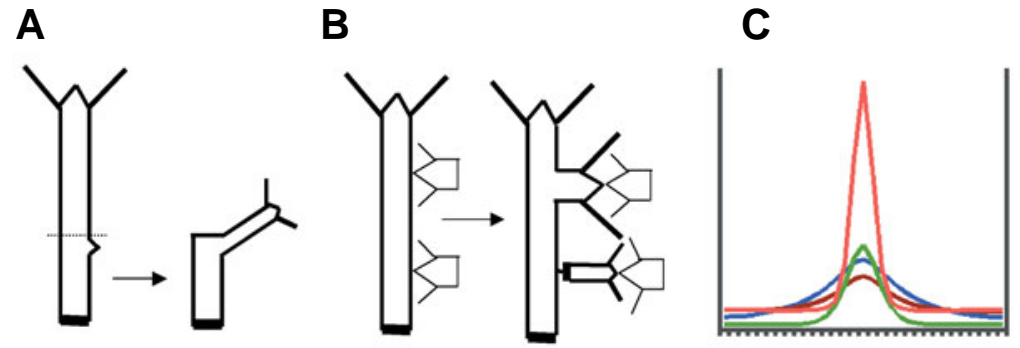

Fig. 3. Branch formation in Hydra. (A) Sectioning distal to a young bud causes the bud to develop into a branch. (B) Transplanting a head with the tip of the hypostome in front, to various body regions causes branch formation if the tissue is transplanted between budding region and head. The implant causes bud formation if it is placed between budding region and basal disc. (C) The simulation was performed in two steps. At first budding was allowed to start as shown in Fig. 1. Then the concentration of the inhibitor $B$ was slightly increased and the simulation was carried on. The increase of the inhibitor $B$ should represent the sectioning in (A) and the transplantation in (B). In both cases a secondary axis is forced to form or continues its growth at an unusual high concentration of inhibitor B, which is found in close vicinity of an existing or regenerating head (for details, see Berking, 2003). 
A
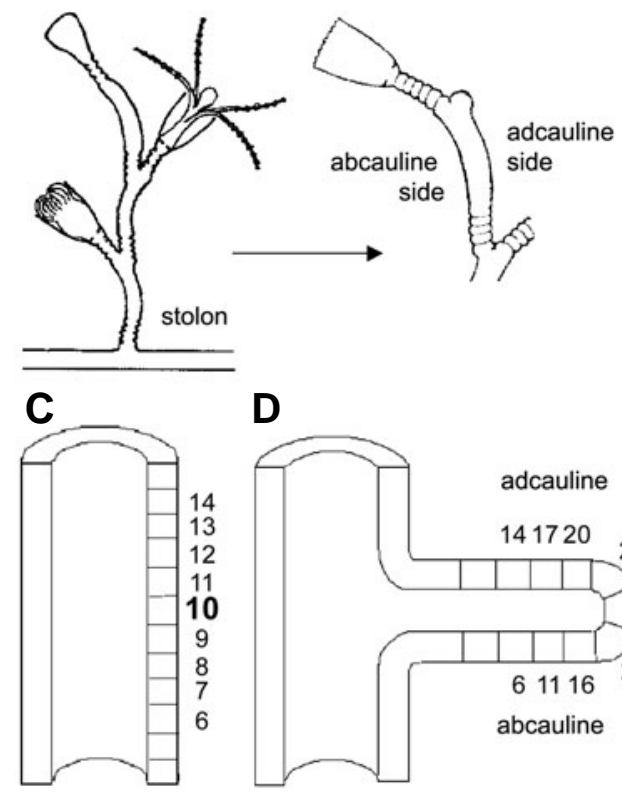

D

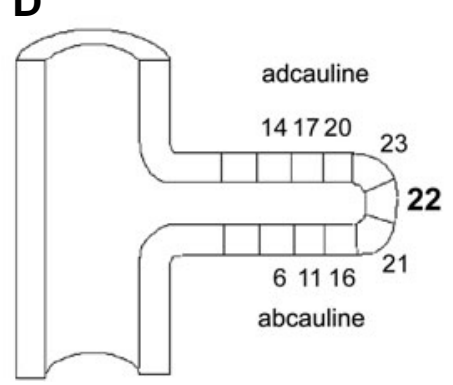

E

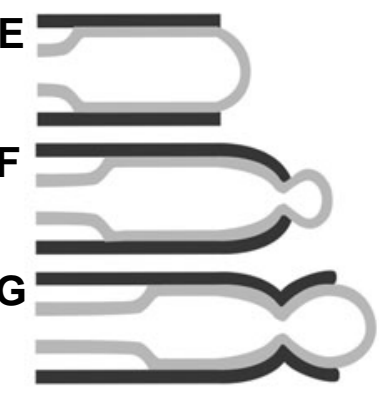

$\mathbf{H}$

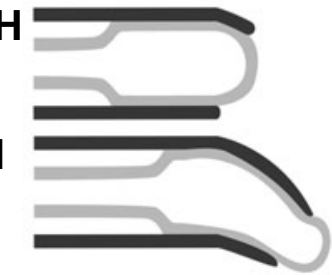

Fig. 4. Shoot growth in Laomedea flexuosa as an example of sympodial growth. (A) Sketch of a small colony. Except for the hydranth only the perisarc lexoskeleton) is shown (after Kossevitch et al., 2001). (B) A branch buds a new branch tip at its adcauline side. (C) Initially the positional values in the tip represent the positional values of the local parent branch tissue. Numbers (arbitrary numbering) indicate the positional values. Number in bold type indicates the future very tip of a new branch. (D) The self-organization processes that causes tip formation also causes the positional value to increase in a graded manner. The positional values are shown after four steps of increase - by 3 units each in the three central cells, in adjacent cells by 2 units and so on. At some distance away from the tip, the positional value must decrease. Note that at a certain distance from the very tip the cells at the adcauline side of the new branch display a higher positional value than those at the abcauline side. This difference causes the next branch bud to form at the adcauline side. (E) The hardened perisarc (black) serves as substrate for the tissue (gray) of the tip to move forward. A subdivision between ectoderm and endoderm is not shown. Behind the tip the tissue tube is no longer in tight contact to the perisarc over its whole surface. The cells of the tip excrete the perisarc material. The apex of the tip is covered with thin, soft perisarc (not shown). The cells of the tip tend to increase the diameter of the tube but the hardened perisarc keeps the diameter from widening. Thus the tube elongates with a constant diameter. (F) The border of hardening has moved closer to the very tip. The tissue tube squeezes through the narrow orifice. (G) The border of hardening has moved to a more proximal position. The forward-moving cells form a bulb with a large diameter. When again the border of perisarc hardening moves closer to the tip, an annulus forms. $(\mathbf{H}, \mathbf{I})$ When the border of perisarc hardening moves asymmetrically closer to the tip, the resulting perisarc tube forms a curve and the diameter decreases.

various specific developments via the positional value. Simulation experiments have shown that a quantitative change of one parameter, such as the local concentration of one of the hypothetical morphogens, is enough to change the developmental fate of a growing tip. During that change, the self-enhanced generation of morphogens is maintained.

\section{Hydrozoa displaying sympodial growth}

The growth pattern described in the following discussion characterizes several species of a suborder of Hydrozoa, the Thecata. These animals form colonies in which all parts are covered with perisarc, a rigid, chitinous, extracellular matrix. Only the polyp can expand out of the tube-like endings of the perisarc covering. Shoot formation generally starts from the top of a hydrorhiza (Fig. $4 \mathrm{~A})$. After a short period of growth, the shoot tip develops into a hydranth. The next step of growth is similar to that of a sympodially growing plant. Some distance from the original apical end, which differentiates terminally (in hydrozoa into a polyp) in a lateral position, the tip of a new branch emerges. This tip takes over the elongation of the shoot.

In several Campanulariidae, repetitive elements consist of two sequences of annuli separated by a smooth, slightly bent tube and followed by the finely structured housing of the polyp, the hydrotheca (Fig. 4A, B). Although the perisarc forms a stiff tube, the indentation between two annuli allows a bending of the tube similar to a joint in arthropods, which are also completely covered by a stiff exoskeleton excluding the joints.

Both the stolon and the shoot tubes lengthen only at their tips (Kühn, 1914; Hyman,1928), by secreting the material that later forms the perisarc (for a review of this process, see Waite, 1990).
Hence the pattern of the perisarc emerges exclusively at that site. Close to the apex of the elongating tube, this secreted material is rather soft and flexible. Its shape is precisely that of the underlying tissue. Some dozens of micrometers proximal to the apex, the perisarc material hardens and from that time onward has a fixed shape. Thus the pattern of the perisarc is a time recording of the tissue activity in the tip.

Experiments performed with Laomedea flexuosaindicate that the cells in the tip shape the perisarc by the following activities (Kossevitch et al., 2001). (1) The cells of the tip move actively forward, displaying a so-called growth pulsation with a periodicity of several minutes (Beloussov, 1973; Hale,1960, 1964; Wyttenbach, 1974). (2) The cells tend to produce a bulb with a larger diameter than the hardened perisarc tube allows. (3) The cells of the tip secrete perisarc material, which hardens at a certain distance to the very tip of the apex. The regulation of this distance largely determines the pattern of the perisarc. When the hardening occurs closer to the apex, the diameter of the ringshaped border between the hard and the soft perisarc decreases (Fig. 4F). That narrowing forces the tissue to squeeze through this small opening. If conditions remain unchanged, the perisarc tube elongates with a reduced diameter. A widening of the diameter takes place when the border of hardening moves to a more proximal position.

The second proposition, the tendency of the tissue tube to attain a larger diameter, is supported by the observation that the tissue tube in the shoot tip has a tight contact to the perisarc over a certain length (about 250 to $350 \mu \mathrm{M}$ in Laomedea flexuosa Hincks, Campanulariidae; diameter of the tissue tube is about 160 to $250 \mu \mathrm{M}$ ), whereas in proximal regions the tissue tube diameter 
is much smaller than the inner lumen of the perisarc tube. Further, the shoot and the stolon occasionally form a bulb at the wound after cutting. The third proposition, the differential control of hardening, has been studied by means of chemicals that interfere with the hardening process (Kossevitch et al., 2001).

\section{Patterning of the branch}

A young tip that is isolated by sectioning develops a complete branch, including the polyp's housing at its end (Kosevich, 1991). The resultant perisarc tube does not contain tissue over its whole length; rather, the tissue of the tip develops into only the most distal part of the hydranth (positioned in the polyp's housing). This development shows that the tissue of the growing tip autonomously determines the perisarc pattern of the branch along its length axis. There is no indication of the existence of a foot/stolon tip system that might influence branch formation, including polyp patterning. The experiment further shows that under normal conditions most of the tissue proximal to the tip is pulled out of the parent shoot by the actively forward-moving tip tissue. Transplantation experiments confirm that distal and proximal tissue has no influence on the patterning of the shoot (Kosevich, 1996).

The simplest explanation of these observations appears to be that by means of a self-organizing process, the positional value continuously increases in the growing tip up to the maximal value possible, as proposed for budding in Hydra. The perisarc is shaped according to the attained value.

The branches of most sympodially growing thecate Hydrozoa display an obvious bilateral symmetry. In Campanulariidae the smooth part of the branch is usually bent and the tip of a new branch develops close to the curve (Fig. 4A, B). There are two possible causes of this asymmetry: Either the branch displays qualitatively different stripes of tissue along its length axis, or within the circumference exists a quantitatively differing tissue parameter. From the evolutionary point of view, we hesitate to propose that so-called Radiata have two qualitatively different body sides, like the dorsal and the ventral side in bilaterians. Thus a more conventional proposition is preferred, that is, a graded distribution of positional values not only in the longitudinal axis but also in the transverse axis of the branch.

Transplantation experiments indicate that in the tissue of the branch tip the cause of the future branch asymmetry is present from the outset (Kossevitch, 2002). I argue that this asymmetry depends on the origin of the branch tissue. Tissue distal to the new branch position (that is, closer to the existing hydranth) has a higher positional value than does tissue proximal to the branch tip (Fig. 4C). Thus, at the outset, the tissue of the new branch tip displays a gradient of positional values along the transverse axis. The highest value is present at the future adcauline side of the branch, namely the side that faces the hydrocaulus of the parent. The tissue that later is pulled out from the parent's hydrocaulus to form the new branch displays the same feature. This initial transverse gradient appears not to vanish completely during outgrowth that includes a change of the positional value along the longitudinal axis (Fig. 4D).

The smooth part of a branch forms when the distance between the position of hardening and the forward-moving tip remains constant (growth pulsations are ignored). Kossevitch et al. (2001) argue that this is caused by a constant secretion of perisarc precursors (Fig. 4E). A row of annuli forms when secretion is not constant but rather oscillates in such a way that the tip cells are entrained to secrete synchronously at a high rate for a short time period (Kossevitch et al., 2001). At least the "hardener" - probably certain phenols (Knight, 1968, 1970; Holl et al., 1992; Kossevitch et al., 2001) - must be secreted in an oscillating manner. A transitory high concentration of hardener moves the hardening border close to the very tip, producing a ring-shaped furrow. When the cells are exhausted and refractory, the border moves back to a proximal position, causing a widening of the developing perisarc tube. Repetitions of the two events, a phase of secretion followed by a refractory phase, cause annuli formation.

Annuli formation starts when the tip cells have attained a certain positional value. The cells that reach first the critical value secrete and entrain the others to do the same. The oscillating secretion ends when a certain higher positional value is attained, causing the transition from the annulated part to the smooth part (Fig. 4A, B). The oscillated secretion starts a second time, causing the formation of the distal annulated zone. Cells that first reach the critical positional value for that transition are positioned at the adcauline side of the branch. They start ahead of the others, with increased secretion, whereas the others in the circumference are still refractory. This causes an asymmetric polymerization of the perisarc tube that results in the observed bending of the smooth part (Fig. $4 \mathrm{H}, \mathrm{I}$ ). In accordance with this proposition, the strongest bending usually appears just before the onset of annulation.

Occasionally the first furrow is not ring-shaped but, rather, restricted to the adcauline part (Kosevich, 2004). In members of the Campanulinae family (for example, in Campanulina lacerata), the hydranth pedicel is often not a row of annuli (distal annulated parts) but a spiral in which one turn matches the diameter of an annulus. Spirals also develop in certain members of the family Sertulariidae (Kosevich, 2004). This observation fits the proposition that a cell secretes certain precursors necessary for perisarc hardening for a short time, followed by a refractory period and that this cell triggers its neighbors also to secrete the same compounds.

\section{Positioning of the branch}

The tip of a new branch develops close to the curve of the smooth part of the branch (Fig. 4B). To learn how the axial position is determined, Kosevich (for review, see Kosevich, 2004) artificially elongated the distal annulated part and found that the new branch tip formed not in the smooth part but rather in the distal annulated zone. This indicates that the axial position of a new branch is controlled similarly to the axial position of a bud in Hydra, by two opposing forces: On the one hand, a high positional value favors the self-organization process to start and on the other hand, the existing head/hydranth exerts an inhibitory influence that antagonizes the onset of that process in its vicinity. These propositions also explain the position of the branch tip in the circumference: Along the branch length axis, the adcauline tissue displays a higher positional value than does the abcauline one (Fig. 4D).

Compared to athecates, thecate Hydrozoa display a much higher variability of form and the number of species is also much higher. The exoskeleton and the spatial and temporal control of its hardening have apparently permitted this strong increase in species number. The arthropods, the bilaterians with the highest variability of body pattern and the highest number of species, also 
Fig. 5. Shoot growth in Dynamena pumila as an example of monopodial growth. (A) Shown is the perisarc (exoskeleton) of a short piece of a shoot of $D$. pumila (after Berking et al., 2002). A shoot can consist of several dozens of the shown repetitive units (internodes) and a colony can produce several dozens of such shoots. The central part of an internode represents the stem and the lateral parts are housings of polyps (hydrotheca). The architecture of the internode at the bottom is unusual: the primordium at the right has not developed into a polyp but rather into a stem tip. The new stem tip causes a normal internode to form. (B - E) Shown is the mode of monopodial growth in Dynamena and a simulation of the change of the positional values at the apical surface of the developing inter-node. (Colors as in Fig. 1.) Initially only one primordium, the stem tip, exists. Because of the widening of the area in which the perisarc is thin and soft (see text), two additional primordia form. All three primordia use the same set of (hypothetical) morphogens. The range of one compound, inhibitor $C$, is so

A

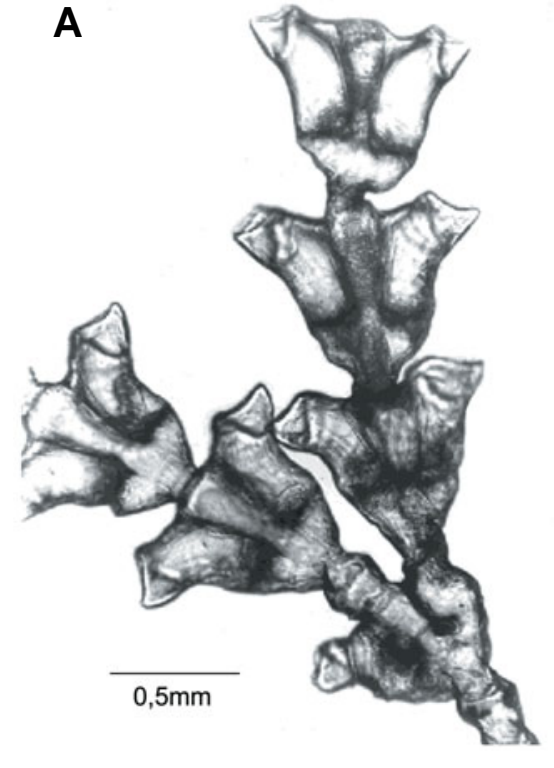

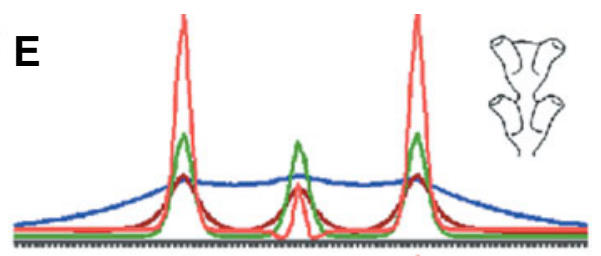

D

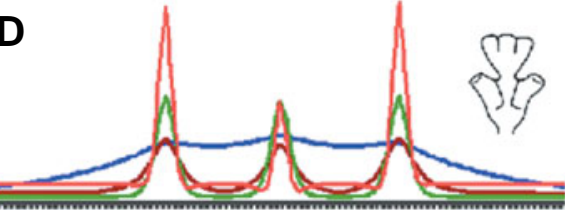

C

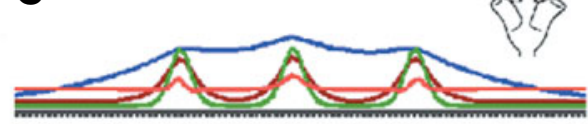

B

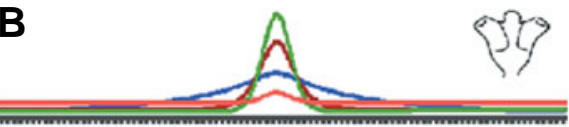
large that the primordia influence each other via this morphogen. Because of its position, the central one is most strongly affected. In this primordium the positional value decreases, whereas in the lateral ones it increases. Because of the positional values reached, the lateral primordia produce a complete hydranth. Where the positional value is maximal, the tip of a hydranth forms. In the central primordium the positional value remains low; it thus remains in a state similar to that of gastric tissue in a polyp. Note that though the central primordium starts ahead of the lateral ones, with a rise in the positional value, it loses the race.

have an exoskeleton. We may thus suggest that the success of arthropods in evolution is also largely based on their ability to develop diverse body patterns, an ability that appears to be largely caused by a spatial and temporal control of the hardening of the arthropod exoskeleton. Even the joints in thecate Hydrozoa and arthropods display similarities.

In summary, the model proposed for Hydra is applied to Laomedea: In a branch tip the positional value increases during growth. The perisarc is shaped according to the attained value. Perisarc precursors are generated by the tip cells in different modes, namely constant or oscillating. The bilateral symmetry of the branch is a result of the gradient of positional values in the tissue that originally forms the bud tip. The position of the branch is proposed to be controlled by two opposing forces: (1) A locally high positional value favors the onset of the self-organizing process that leads to branch formation and (2) by lateral inhibition the existing self-organizing process in the hydranth prevents the formation of a new one in its vicinity.

\section{Hydrozoa displaying monopodial growth}

Monopodial growth in Athecata and Thecata is very different: In Athecata the shoot ends in a polyp and elongates by intercalary growth caused by cell multiplication (Fig. 2B). When a certain length is reached, a branch forms in lateral position. The end of the branch develops into a polyp. Both the shoot and the branch elongate and form a further branch, when a certain length is reached and so on.

This type of growth has strong similarities to growth and budding in Hydraand in particular to experimental branch formation in Hydra. It doesn't appear necessary to posit a patternforming system specific for Athecata displaying such a type of growth.
In Thecata an intercalary elongation of the shoot does not exist, because of the perisarc covering of the whole colony including the polyp (Fig. 5). The elongating end of the shoot is occupied by a stem tip that behaves like a shoot apical meristem in seed plants. It grows by maintaining its character while right and left polyps emerge in a repetitive manner like leaves in higher plants. When a stem of Dynamena pumila grows in length, generally three primordia form out of the initial single one. The two lateral ones develop into polyps; the central one elongates, subdivides into three primordia and thus starts a new cycle of internode formation.

\section{Patterning of the branch}

To explain how the new "organ" stem tip becomes organized, we can assume the existence of an additional pattern-forming system, including a set of new morphogens. This rises several questions: How can the evolution of this system be explained within the group of Thecata? How do primordia that develop differently appear at the apex of a stem at a certain distance from each other? Either primordia use identical inhibitors, or different inhibitors cross-react to some extent in the other systems-they cannot keep their distance in different ways. And we must also explain how primordia that follow a different development become arranged properly. Generally, the stem tip develops in the center and right and left polyps develop; other arrangements are rarely observed (Fig. 5, Fig. 6). A general requirement for all models of pattern formation is also to explain such rare arrangements.

The following discussion shows that all these problems can be solved by assuming that the system used for bud formation in Hydraand branch formation in Laomedea (and other sympodially growing Thecata) also controls pattern formation in Dynamena (and other monopodially growing Thecata). The most important 

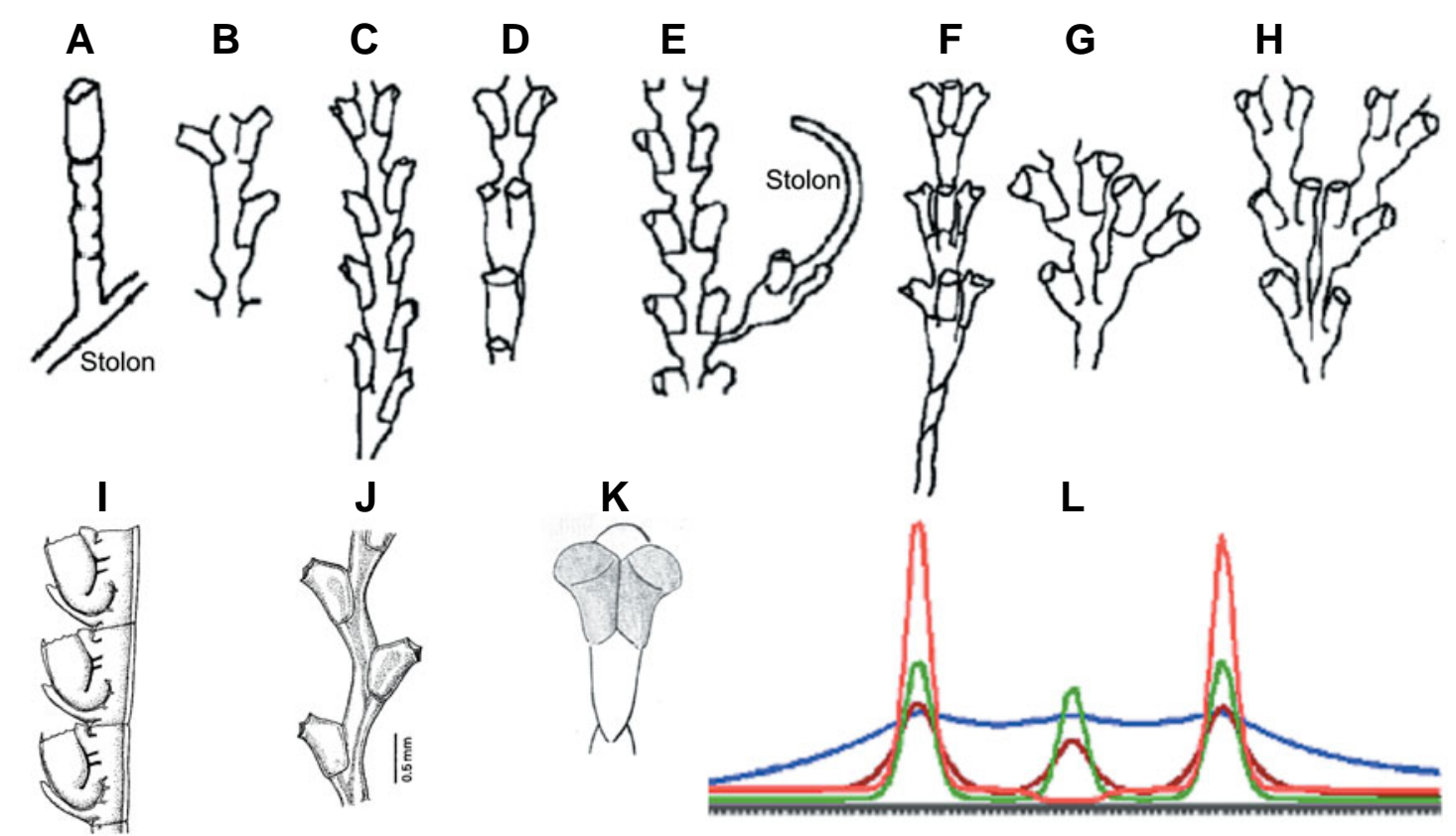

Fig. 6. Morphotypes of Dynamena pumila and internodes of species related to Dynamena. (A to H) A selection of morphotypes or malformations of D. pumila (Marfenin et al., 1995; Berking et al., 2002). Shown are the exoskeletons. In one case the central primordium develops a stolon instead of a stem tip (E). The respective simulation (L) shows that a stolon forms if the three primordia remain in tight contact with each other for a long time. Note that in the central primordium the positional value (red line) reaches almost zero. (I) Lytocarpia myriophyllum (J) Sertularella gayi (I,J after Cornelius et al., 1995). (K) Sketch of a growing tip of a species of Sertularia, displaying the two hydranths (gray) at one, the "ventral" side (Kühn, 1909).

differences among the pattern-forming systems of these animals are the activity ranges of the (hypothetical) morphogens in the respective tissues.

The development of a repetitive unit, an internode, starts with a small stem tip in which the cells of the apex have a certain positional value and the activity of the (proposed) pattern-forming system increases this value (Fig. 5B to E). The cells actively move forward, using the already hardened perisarc as substrate (as observed in Laomedea) and produce a spherical bulb at the apex, indicating that the tissue moves faster than the border of perisarc hardening. The widened apical surface of the bulb is covered only by thin, soft perisarc. This is the moment at which (generally) out of one primordium, three primordia form. Applying the model proposed for pattern formation in Hydra, the following sequence of events is suggested (Berking et al., 2002): From the apex tissue, the loss of the (hypothetical) inhibitors is larger than from tissue covered by thick and rigid perisarc. This results in a selfenhanced release of the activator not only in the center of the tip but also in the surroundings. By autocatalysis and lateral inhibition, additional primordia form. All primordia use the same set of morphogens. The inhibitor that decreases the positional value (inhibitor $\mathrm{C}$ ) is proposed to have a range sufficient to reach the primordia in the neighborhood.

Obviously, the primordium in the center is most strongly affected. Its positional value decreases, whereas in the lateral primordia the positional value increases (Fig. 5E). The lateral primordia develop into polyps; the central primordium remains in a state similar to that of gastric tissue. Histological studies show that in the course of growth the central primordium becomes increasingly more isolated from the developing polyps that are in the lateral position (Berking et al., 2002). Isolation reduces the influence of the lateral primordia on the central primordium and in the central one it allows the positional value to increase again: The next cycle of internode formation has started.

I propose that all primordia, taken together, are organized in the same way by the same set of morphogens. The central primordium develops into a stem tip simply because of its position. In the central primordium, the positional value increases and decreases once in each internode cycle, without reaching the maximal and the minimal value. Such a mechanism has an inherent instability, which is proposed to explain the high number and the nature of malformations observed in D. pumila (up to $1 \%$ of all internodes): Quantitative changes of external influences cause a quantitative change of the «lateral dominance.» A small lateral dominating influence allows the central primordium to develop into a polyp (Fig. 6F). A very strong such influence causes the central primordium to develop into a stolon (Fig. 6E, $\mathrm{L})$. The point of interest here is that with respect to these morphotypes a rule governs the spatial arrangement of primordia that develop differently. When three or more primordia form, the tip of the central primordium usually develops a lower - rarely an equal, but never a higher - positional value than the tip of a lateral primordium. This strongly indicates that primordia form so close to each other that they influence each other's developmental fate. No exception to the rule has yet been found, although far more than 200,000 internodes have been studied (Marfenin et al., 1995: Berking et al., 2002).

\section{Positioning of the branch}

In Dynamena, as argued for Hydra and Laomedea, I propose that two opposing forces determine where branch formation starts: A high positional value favors the onset of the selforganizing processes and one self-organizing process prevents the onset of a further one close to it. These propositions explain 
that in Dynamenaand related species, polyps and stem tip keep a regulated distance from each other. These propositions also explain that in successive internodes the polyps form as closely as possible to each other. Usually polyps form in rows along the longitudinal axis (Fig. 5). This pattern is caused by a particular feature of the shoot tips: In the tip, cell proliferation is very rare (for review, see Kosevich, 2004). Thus the new primordia that form in lateral position include tissue that derives from tissue proximal to the tip (as observed in Laomedea, sympodial growth). This tissue has a differential origin in the circumference. Tissue at a certain position derives from or is influenced by the adjacent hydranth primordium; tissue at other positions is not. Thus in successive internodes polyps form in longitudinal rows. They form in tissue that at the outset has a higher positional value than does other tissue lying at the same distance to the existing stem tip. The very same proposition has been made for branch positioning in thecates with sympodial growth (see earlier discussion). With respect to Dynamena, to my knowledge such an export of tissue out of a hydranth into the surroundings has not been demonstrated to occur but has been shown for Hydractinia echinata(Müller, 1964).

It appears that in contrast to Hydra and sympodially growing Thecata, monopodially growing Thecata have developed an additional way of controlling where primordia form and how many form. In all Thecata, the positional value controls the area of the tip that is not covered by hardened perisarc. Only in Thecata with monopodial growth do new primordia form within this area (secondary branches and gonozoids, both of which form late, are ignored). The size of this area determines how many additional primordia can form. Thus a self-organizing process controls, via the positional value and via the resulting morphodynamics, the position and the number of additional self-organizing processes. Several malformations appear to support this proposition: When the apical area that is covered with thin, soft perisarc remains so small that additional primordia cannot begin to form, the stem simply elongates (Fig. 6A). When there is a large loss of inhibitors, a hydranth forms out of the tip (Fig. 6A). When the area is larger, two primordia form. Because of the interaction noted, one primordium remains a stem and the other develops into a hydranth (Fig. 6B). In one malformation (Fig. 6D), two primordia formed (bottom): One developed into a stem tip, the other into a hydranth. In a next step three formed; the two hydranth-forming primordia are close to each other and symmetrically positioned "above" the old one. The new ones formed at the right and the left margins of the hypothetical polyp-derived tissue imported into the widened stem tip. The position of the two hydranth primordia is determined by the two opposing conditions noted, (1) the local high positional value of the tissue and (2) the mutual lateral inhibition of the two developing primordia. Accordingly, in a third step the hydranths form at a greater distance from each other. The hydranths form in an axial line because of the export of tissue with a high positional value (Fig. 6l), indicating that the imported tissue displays a higher positional value than does the stem tip. An alternate positioning of hydranths (Fig. $6 \mathrm{C}, \mathrm{J}$ ) is caused by the two opposing influences if the area is just too small to allow three primordia to develop simultaneously. How close to each other three or more primordia form is determined by the two opposing forces: (1) the high positional value of the imported tissue and (2) the range of the inhibitor involved in distance control. If the lateral inhibition has a

Local positional value (pv) determines local developmental fate in tissue and perisarc. High pv favors onset of new self-organizing process; one activator, two inhibitors: activation of patch of cells. Increase of pv there, decrease in periphery $=$ fate control. Lateral inhibition $=$ distance control

Range of fate control larger than range of distance control

Due to lateral dominance two types of branches:

(1) pv increases in tip: branch develops into hydranth. (2) pv increasing / decreasing once within internode cycle: shoot tip

Shoot elongation by permanently existing tip Thecata

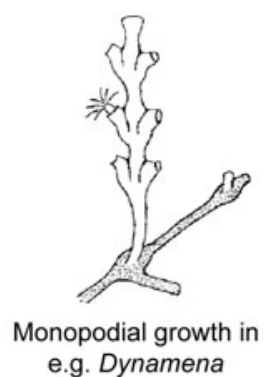

Range of fate control smaller than range of distance control

Increase of pv in tip causes branch formation: tip forms hydranth

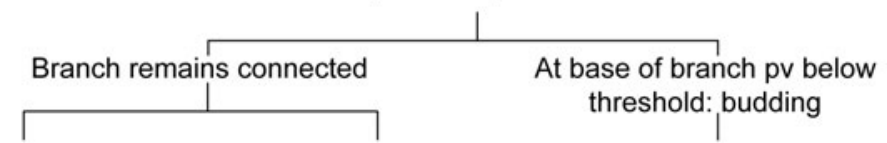

Shoot elongation by repeated lateral branching Thecata

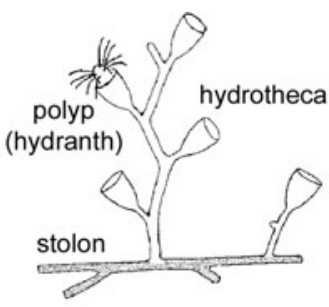

Sympodial growth in e.g. Laomedea
Shoot elongation by intercalary growth: lateral branches Athecata

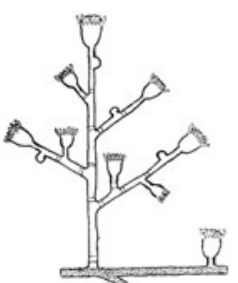

Monopodial growth in e.g.Cordylophora
Intercalary growth: lateral buds Athecata

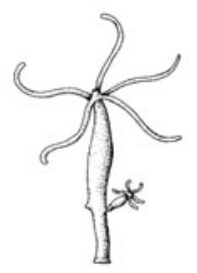

Budding in e.g. Hydra

Fig. 7. Principles of branch formation and branch patterning in Hydrozoa. 
long range, primordia form opposite to each other. If the range is short, hydranths form close to each other. Two genera (Diphasia, Sertularia) have developed shoots with a "ventral" side (Kühn, 1914), a "Zoidfläche" (Weismann, 1883) at which hydrotheca form very close to each other, indicating a comparatively short range of distance control (Fig. 6K).

The similarity to plants is obvious. Meinhardt et al. (1998) proposed that leaf primordia keep their distance from each other by signals that involve autocatalysis and lateral inhibition. In plants, most of the tissue that forms a leaf derives from the meristem, the growing stem tip. In Thecata, most of the tissue that forms the new primordium derives not from the stem tip but from the proximal position of the tissue tube. Therefore in Hydrozoa two opposing forces control the position of primordia formation, whereas in plants lateral inhibition appears to play the most important role (Meinhardt et al., 1998). This difference appears to explain why certain arrangements of polyps have not been found-for example (to my knowledge), a spiral arrangement, such as is seen in several plants.

Researchers have proposed that mechanical influences cause three primordia form out of one primordium (Beloussov, 1975; Beloussov and Grabovsky, 2003). These authors suggest that differential development of the tissue in the growing tip is preceded by a differential shaping of that tissue. The shaping is caused by a shift in the region of maximal active stretching of the tip's tissue in base-to-apex direction within one growth pulsation. Thus, out of one center of pulsation several primordia develop that may display different pulsation properties. The pattern of these new primordia is determined by the mechanical properties of the tissue of the tip's surface. If the mechanical forces trigger the onset of the various specific developments such as polyp, stem, or stolon formation, we must explain how a different mechanical stretching of tissue can cause a different onset of gene activity. However, the interactions proposed here that may use diffusible substances could hardly directly alter the physical form of the tissue layer. The step between the proposed signaling and the resultant structure, such as polyp, stolon, or stem, certainly is an alteration of cell activities, including a change of growth pulsation in the epithelial sheet of the tip surface.

\section{Stolon Formation}

The stolon tip has features in common with the tip of a shoot: The tissue of the tip is covered by perisarc, with which it has tight contact-excluding the very tip, where the perisarc is soft and thin. The stolon does not form structures such as annuli. It elongates without forming a structure terminally. It produces stolon branches laterally and shoot branches from the roof. Stolons fix to a surface and thus become asymmetric. In some species they accompany the shoot, which results in the formation of very complex colonies. A detailed discussion of stolon formation and stolon patterning is not intended here; I discuss only one question: Is stolon formation controlled by a system different from that in shoot branch formation? I propose that one system controls both shoot and stolon formation. A stolon tip forms when the positional value falls to the lowest value possible. However, other than with basal disc regeneration in Hydra, the pattern-forming system is not switched off. A possible cause for that switched-on mode may be a sufficiently high basal, unregulated production of the agent that determines the positional value. This production level results in endless growth without a change in the positional value at the tip and thus without structure formation.

\section{Conclusion}

Branch formation in Hydrozoa is organized by a patternforming system with self-organizing properties that makes use of at least three morphogens (Fig. 7). The system does not control structure formation directly but, rather, regulates the quantity of a tissue parameter (for example, within cells the concentration of a compound involved in regulation) in such a way that a gradient in the tissue forms. The local quantity of this parameter, termed positional value, determines the local developmental fate, such as hypostome (highest positional value), tentacles and basal disc. A gradient and a body length axis are not postulated to exist $a$ priori.

The system controls branch tip formation and is kept active in the tip even when it differentiates in a hypostome of a polyp. Where the system is active, cell proliferation is rare. A high positional value favors the onset of a new self-organizing process and by lateral inhibition a self-organizing process prevents the formation of a further one in the vicinity. Small differences in the activity range/strength of the signals involved in self-organization allow in certain species a decrease of the positional value to the lowest value possible that causes the formation of a basal disc and separation from the parent (budding). In monopodiallygrowing thecate Hydrozoa, the activity that can decrease the positional value is proposed to have a longer range than the one that controls the distance between primordia (Fig. 7). In sympodially growing thecate Hydrozoa, the reverse is proposed to be true. This is suggested to be the essential difference between the primary pattern-forming systems of monopodially growing thecate Hydrozoa and those of sympodially growing thecate Hydrozoa. Interestingly, several species display transitional forms between a purely sympodial and a purely monopodial growth pattern (Kühn, 1914). Basal disc regeneration in Hydra is controlled by the same system, including the very same morphogens. When the lowest positional value is reached, a basal disc forms and the system is switched off. In stolon formation the system is not switched off, because of a certain basal production of morphogens that causes an endless maintenance of the activity and an endless elongation of the stolon.

In seed plants the shoot apical meristem is well studied. However, the control of its origin in embryogenesis and its maintenance during growth is still a matter of research. If the shoot apical meristem is formed and maintained in a way similar to that proposed for monopodially growing thecate Hydrozoa, the meristem must be understood as a leaf primordium that laterally developing leaf primordia block from developing into a leaf.

The developmental morphodynamics of branch formation in Hydrozoa can be subdivided into two parts: Hydrozoa elongate their branches by cell recruitment and intercalary cell proliferation. Species in which an exoskeleton cover the branches combine this intercalary tissue growth with a terminal elongation of the perisarc tube. As in Arthropoda, the exoskeleton of Hydrozoa includes stiff and jointlike parts. In Hydrozoa the formation of these structure elements is controlled by the actual positional 
value of the tissue in the growing tip. The positional value controls the position of perisarc hardening. Cells that cause the zone of hardening to move close to the very tip trigger their neighbors to do the same. Then the cells become refractory, which causes the zone of hardening to move to a proximal position. This causes a ring-shaped furrow to form, followed by a widening of the perisarc tube. In monopodially growing Thecata, the branch primordia form within the area that is not covered by thick, hardened perisarc. If this area is small, new primordia do not form. In monopodially growing Thecata, morphodynamics controlled by the local positional value apparently control the onset of new selforganizing processes.

\section{Models and molecular approaches}

Advanced molecular techniques have yet to be developed for Hydrozoa. Most studies are still based on expression patterns of candidates of control genes and putative markers of certain specific developments. Results obtained are compared with those obtained following treatments with certain chemicals or by other techniques such as sectioning and transplantation. The links between these various approaches are models. Models can summarize experimental data in that the system properties of the studied processes become transparent. Certainly they cannot replace studies at the cellular and the molecular level, but they can help researchers find and evaluate the critical components. One example is given here; a more detailed discussion is published elsewhere (see Berking, 1998, 2003).

With respect to Hydra, Wntsignaling has been suggested to be an element of the "head organizer" (Hobmayer et al., 2000). The arguments are that HyWnt and other members of the Wntpathway ( $H y \beta c a t$ and $H y T C$ ) are expressed in the hypostomal tip, early in head regeneration and also early in budding. However, HyWnt and in particular Hy $\beta$ cat (HyTcf was not tested) are also expressed in foot-regenerating tissue, although more weakly and only transiently (Hobmayer, personal communication, in Berking, 2003). The question therefore is, Can this weaker, transient expression during foot regeneration be ignored, or is it important? The same set of morphogens control both head and foot regeneration. The tissue adjacent to the wound determines the fate at the wound. If the positional value decreases down to the lowest value possible, a foot forms and morphogen generation ceases. Hence Wnt signaling can have a more fundamental relevance than originally proposed. It is not head specific but, rather, is a good candidate for an element of the pattern-forming system that controls the positional value.

\section{Acknowledgments}

I thank K. Herrmann and I. Kosevich for helpful discussions.

\section{References}

BELOUSSOV, L.V., (1973). Growth and morphogenesis of some marine Hydrozoa according to histological data and time-lapse studies. In Recent trends in research in coelenterate biology (Eds. T. Tokioka and S. Nishimura). The Proceedings of the second international symposium on Cnidaria. Publs Seto mar. biol. Lab. 20: 315-366.

BELOUSSOV, L.V. (1975). Possible ontogenetic mechanism governing formation of the body plans in animal embryos. Verh. Dtch. Zool. Ges. 89: 219-229.

BELOUSSOV, L.V. and GRABOVSKY, V.I. (2003). A geometro-mechanical model for pulsatile morphogenesis. Comput. Methods Biomech. Biomed. Engine 6: 53-63.

BERKING, S. (1979). Analysis of head and foot formation in Hydraby means of an endogenous inhibitor. W. Roux's Arch. 186: 189-210.

BERKING, S. (1998). Hydrozoa metamorphosis and pattern formation. Curr. Top. Dev. Biol. 38: 81-131.

BERKING, S. (2003). A model for budding in Hydra: pattern formation in concentric rings. J. Theor. Biol. 222: 37-52.

BERKING, S., HESSE, M. and HERRMANN, K. (2002). A shoot meristem-like organ in animals. Monopodial and sympodial growth in Hydrozoa. Int. J. Dev. Biol. 46: 301-308.

BODE, P.M., AWAD, T.A., KOIZUMI, O., NAKASHIMA, Y., GRIMMELIKHUIJZEN, C.J.P. and BODE, H.R. (1988). Development of the two-part pattern during regeneration of the head in Hydra. Development 102: 223-235.

BRAVERMAN, M. (1971). Studies on hydroid differentiation. VII. The hydrozoan stolon. J. Morph. 135: 131-152.

BURNETT, A.L. (1961). The growth process in Hydra. J. Exp. Zool. 146: 21-83.

CORNELIUS, P.F.S., MANUEL, R.L. and RYLAND, J.S. (1955). Hydroids, Sea Anemones, Jellyfish and Comb Jellies. In Handbook of the Marine Fauna of North-West Europe (Eds. Hayward, P.J., Ryland, J.S.) Oxford University Press, Oxford New York Tokyo.

DAVID, C.N. and CAMPBELL, R.D. (1972). Cell cycle kinetics and development of Hydra attenuata. I. Epithelial cells. J. Cel/ Sci. 11: 557-568.

GIERER, A. and MEINHARDT, H. (1972). A theory of biological pattern formation. Kybernetik 12: 30-39.

GIERER, A., BERKING, S., BODE, H., DAVID, C.N., FLICK, K., HANSMANN, G., SCHALLER, H. and TRECKNER, E. (1972). Regeneration of Hydra from reaggregated cells. Nature, New Biol. 239: 98-101.

HALE, L.J. (1964). Cell movements, cell division and growth in the hydroid Clytia johnstoni. J. Embryol. Exp. Morph. 12: 517-538.

HALE, L.J. (1960). Contractility and hydroplasmic movements in the hydroid Clytia johnstoni. Quart. J. Microscop. Sci. 101: 339-350.

HOBMAYER, B., RENTZSCH, F., KUHN, K., HAPPEL, C.M., CRAMER VON LAUE, C., SNYDER, P., ROTHBÄCHER, U. and HOLSTEIN, T.W. (2000). WNT signalling molecules act in axis formation in the diploblastic metazoan Hydra. Nature 407: 186-189.

HOLL, S.M., SCHAEFER, J., GOLDBERG, W.M., KRAMER, K.J., MORGAN, T.D. and HOPKINS, T.L. (1992). Comparison of black coral skeleton and insect cuticle by a combination of carbon-13 NMR and chemical analyses. Arch. Biochem. Biophys. 292: 107-111.

HYMAN, L. (1928). Miscellaneous observations on Hydra, with special reference to reproduction. Biol. Bull. 54: 65-108.

KNIGHT, D.P. (1968). Cellular basis for quinone tanning of the perisarc in the Thecate hydroid Campanularia (= Obelia) flexuosaHinks. Nature218:584-586.

KNIGHT, D.P. (1970). Sclerotization of the perisarc of the caliptoblastic hydroid, Laomedea flexuosa. 1. The identification and localization of dopamine in the hydroid. Tissue \& Cell 2. 467-477.

KOSEVICH, I.A. (1991). Comparison of functioning of the sprout and stolon growth apices in the colony of Obelia loveni (Allm.) (Hydrozoa, Campanulariidae). Vestn. Mosk. Univ., Ser.16: Biol., no 2: 44-52.

KOSEVICH, I.A. (1996). Regulation of formation of the elements of the hydroid polyps colony. Russian J. Dev. Biol. 27: 95-101, Translated from Ontogenez (1996) 27: 114-121.

KOSEVICH [KOSSEVITCH], I.A., HERRMANN, K. and BERKING, S. (2001). Shaping of colony elements in Laomedea flexuosaHinks (Hydrozoa, Thecaphora) include a temporal and spatial control of skeleton hardening. Biol. Bull. 201:417423.

KOSEVICH [KOSSEVITCH], I.A. (2002). Role of the skeleton in determination of the branching points in hydroid colonies. J. Obshchej Biologii. 63: 40-49.

KOSEVICH, I.A. (2004). Branching in colonial hydroids. In Branching Morphogenesis (Ed. Davies, J). Landes Bioscience.

KÜHN, A. (1909). Sprosswachstum und Polypenknospung bei Thecaphoren. Studien zur Ontogenese und Phylogenese von Hydroiden. Zool. Jb. Anat. 28: 387-476.

KÜHN, A. (1914). Entwicklungsgeschichte und Verwandschaftsbeziehungen der 


\section{S. Berking}

Hydrozoen. 1. Teil: Die Hydroiden. Erg. Fortschr. Zool. 4: 1-284.

MARFENIN, N.N., MARGULIS, R.J. and MEIER, E.M. (1995). Morphological variability of the colonial hydroid Dynamena pumila, with classification of found morphotypes. Russian Academy of Sciences. Proceedings of the Zoological Institute St. Petersburg. 261: 71-89 (Russian).

MEINHARDT, H. (1993). A model of biological pattern formation of hypostome, tentacles and foot in Hydra: How to form structures close to each other, how to form them at a distance. Dev. Biol. 157: 321-333.

MEINHARDT, H., KOCH, A.J. and BERNASCONI, G. (1998). Models of pattern formation applied to plant development, In Symmetry in Plants. (Eds. D. Barabe and R.V. Jean) World Scientific Publishing, Singapore: 723-758.

MÜLLER, W. A. (1964). Experimentelle Untersuchungen über Stockentwicklung, Polypendifferenzierung und Sexualchimären bei Hydractinia echinata. Roux's Arch. Dev. Biol. 155: 181-268.

OTTO, J. J. and CAMPBELL, R. D. (1977). Budding in Hydra attenuata: bud stages and fate map. J. exp. Zool. 200(3): 417-428.

PLICKERT, G., HERINGER, A. and HILLER, B. (1987). Analysis of spacing in a periodic pattern. Dev. Biol. 120: 399-411.

RULON, O. and CHILD, C.M. (1937). Observations and experiments on developmental pattern in Pelmatohydra oligactis. Physiol. Zool. 10: 1-13.

SANYAL, S. (1966). Bud determination in Hydra. Indian J. Exp. Biol. 4: 88-92.

SHOSTAK, S. (1974). Bipolar Inhibitory gradients' influence on the budding region of Hydra viridis. Am. Zool. 14: 619-632.
TARDENT, P. (1972). Experimente zum Knospungsprozess von Hydra attenuata Pall. Rev. Suisse Zool. 79: 355-375.

TARDENT, P. (1978). Coelenterata, Cnidaria. In Morphogenese der Tiere (Ed. Seidel, F.). Stuttgart New York: Gustav Fischer Verlag.

von SCHENCK, D.A. (1965). Die Kormentektonik der Plumulariiden (Coelenterata, Hydrozoa). Rev. Suisse Zool. 72: 885-1021.

WAITE, J.H. (1990). The phylogeny and chemical diversity of quinone-tanned glues and varnishes. Comp. Biochem. Physiol. 96B: 19-29.

WEBSTER, G. and HAMILTON, S. (1972). Budding in Hydra: The role of cell multiplication and cell movement in bud initiation. J. Embryol. exp. Morph. 27: 301-316.

WEIMER, B.R. (1928). The physiological gradients in Hydral. Re-constitution and budding in relation to length of piece and body level in Pelmatohydra oligactis. Phys. Zoöl. 1: 183-230.

WEISMANN, A. (1883). Die Entstehung des Sexuallebens bei den Hydromedusen. Jena.

WOLPERT, L. (1969). Positional information and the spatial pattern of cellular differentiation. J. theor. Biol. 25: 1-47.

WOLPERT, L., HORNBRUCH, A. and CLARKE, M.R.B. (1974). Positional information and positional signalling in Hydra. Am. Zool. 14: 647-663.

WYTTENBACH C.R. (1974). Cell movements associated with terminal growth in colonial hydroids. Am. Zool. 14: 699-717. 